\title{
ROCQ MORRIS, PSEUDÓNIMO DE MERCEDES BALLESTEROS SUS NOVELAS POLICIACAS DE QUIOSCO
}

ALBERTO GARCÍA-AGUILAR

Universidad de La Laguna agarciaa@ull.edu.es

RESUMEN: Las cuatro novelas policiacas que Mercedes Ballesteros publicó con el pseudónimo de Rocq Morris en los primeros años del franquismo, en la colección de quiosco "La Novela Ideal", incluyen muchos de los estereotipos usados en la narrativa criminal española de este periodo. En todas ellas, detectives aficionados, que viven entre ricos, tratan de descubrir al asesino enfrentándose al rechazo policial e incluso a la violencia física. De esta manera, la escritora ofrece historias destinadas al ocio de los lectores donde los detectives siempre triunfan.

PALABRAS CLAVE: novela policiaca, novela de quiosco, narrativa popular, Mercedes Ballesteros. 


\section{ROCQ MORRIS, MERCEDES BALLESTEROS'S PEN NAME: her Crime Kiosk Novels}

ABSTRACT: The four crime novels published by Mercedes Ballesteros under the pen name of Rocq Morris in the first years of the Francoist dictatorship, in the kiosk series "La Novela Ideal" include many of the stereotypes deployed by the Spanish criminal narrative during this same period. In all of them, amateur detectives, who live among wealthy people, attempt to discover the murderer despite facing police rejection and even physical violence. In this way, Ballesteros offer popular narratives intended for the leisure of the readers in which detectives always succeed.

KEY WORDS: crime novel, kiosk novel, popular narrative, Mercedes Ballesteros.

\section{Introducción}

a obra de Mercedes Ballesteros (Madrid, 1913 - Madrid, 1995) ha reciLido una escasa atención por parte de los estudiosos ${ }^{1}$. Las investigaciones relacionadas con su producción literaria se centran en los textos teatrales (Plaza Agudo, 2012), en las novelas cortas (Pujante Segura, 2010) y en las novelas rosas (Soler Gallo, 2017), pero la narrativa policiaca de quiosco ha quedado olvidada. Ello se debe, sobre todo, al desdén general con el que se considera desde el ámbito académico este tipo de narrativa popular, destinada al ocio de los lectores. A pesar de formar parte del entorno de la Generación del 27 (Merlo, 2010: 71), de destacar como escritora de novela corta (Fernández Gutiérrez, 2004: 23) y de ser una de las primeras mujeres en publicar novela policiaca en los primeros años del franquismo,

${ }^{1}$ Trabajo cofinanciado por la Agencia Canaria de Investigación, Innovación y Sociedad de la Información de la Consejería de Economía, Industria, Comercio y Conocimiento y por el Fondo Social Europeo (FSE) Programa Operativo Integrado de Canarias 2014-2020, Eje 3 Tema Prioritario 74 (85\%). tal como señalan Godsland (2007: 2) y Vosburg (2011: 76), de estas narraciones de Ballesteros no existe ningún estudio. Autores como Vázquez de Parga (1993: 100; 2000: 33, 64), Santiago Mulas (2002: 608-610), Charlo (2005: 109) y Reverón Alfonso (2007: 219) mencionan su faceta como novelista policiaca en la colección "La Novela Ideal" y en Ediciones Océano, pero no desarrollan ningún análisis sobre la cuestión. Por eso, el presente trabajo intentará realizar un estudio detenido de las cuatro narraciones de este subgénero ${ }^{2}$ que la autora publicó con el pseudónimo de Rocq Morris: City Hotel (1938), París-Niza (1939), El cofre de las piedras azules (1940) y Cena siniestra (1944).

Para ello, se establecerá primero la relación que mantuvo Mercedes Ballesteros con "La Novela Ideal", colección en la que aparecen tres de estas cuatro novelas. A continuación, se determinará cómo se reflejan en estas narraciones diversos aspectos que conformaban la idiosincrasia de la novela criminal española de los comienzos del franquismo. Así, recurriendo a las primeras ediciones de las obras, se analizará el modo en el que se favorece la evasión de los lectores gracias al ambiente aristocrático y lujoso en el que viven los personajes. También se estudiará la función que desempeñan los investigadores encargados de resolver los crímenes y la manera en la que consiguen el éxito, ligada a la búsqueda activa de evidencias, a la astucia y, en ocasiones, al carácter aventurero. De esta manera, se ofrecerá una visión detallada de cómo Ballesteros reproducía en sus obras las situaciones y los arquetipos propios del subgénero que triunfaban en los primeros años de posguerra.

\section{Mercedes Ballesteros y la literatura de quiosco: la colección "La Novela Ideal"}

Mercedes Ballesteros, desde su infancia, vivió en un estimulante ambiente intelectual. Tanto su padre, Antonio Ballesteros Beretta, como su

${ }^{2}$ Dada la confusión terminológica en torno al concepto de subgénero literario, en este trabajo se empleará con el sentido que le da el crítico Kurt Spang, quien entiende por tal las subdivisiones - en este caso temáticas - de las "formas de presentación literarias o géneros teóricos, es decir, la narrativa, la dramática y la lírica" (2000: 18). 
madre, Mercedes Gaibrois Riaño, destacaron como historiadores, al igual que su hermano Manuel Ballesteros Gaibrois. Pronto sintió inquietudes literarias, de tal manera que, durante la adolescencia, publicó dos poemarios: Poesías (1925) e Iniciales (1929). No obstante, años después, su esposo, Claudio de la Torre ${ }^{3}$, en una carta que envía al escritor canario Fernando González Rodríguez en 1941, quita importancia a estos poemas aludiendo a la corta edad de Ballesteros cuando los escribió. Además, le informa de que ella ha abandonado la poesía: "No le he mandado ningún verso de mi mujer porque ya ella no ha vuelto a escribir ninguno desde hace muchos años, y los últimos que publicó, teniendo catorce, no merecen figurar en ninguna antología" (Torre, 1941 [13 de enero]: 1).

Su tercera obra, la pieza teatral Tienda de nieve, aparece en 1932, aunque nunca se representó (Plaza Agudo, 2012: 26). Al año siguiente, con dieciocho años, se casa con Claudio de la Torre, que ya había ganado en 1924 el Premio Nacional de Literatura por su novela En la vida del señor Alegre. En la revista Blanco y Negro, con motivo de este enlace matrimonial, se habla de los contrayentes como de "dos personalidades destacadas en la nueva literatura" ("Bodas recientes", 8 de enero de 1933: 73). A partir de entonces se sucederán las publicaciones que conforman la mayor parte de su extensa producción literaria. Incluso, después de la Guerra Civil española, colabora en la revista La Codorniz con el pseudónimo de Baronesa Alberta. Además, en un concurso convocado por la colección "La Novela del Sábado", especializada en novela breve, Ballesteros gana en 1954 el primer premio con su novela Eclipse de tierra (Fernández Gutiérrez, 2004: 23). Sin embargo, tras el comienzo de la Guerra Civil, sus primeras publicaciones aparecen en la colección "La Novela Ideal" (1938-1944), que surge como una iniciativa de su marido, de Josefina de la Torre ${ }^{4}$-hermana de Claudio- y de la propia Ballesteros.

${ }^{3}$ Claudio de la Torre (Las Palmas de Gran Canaria, 1895-Madrid, 1973) desarrolló actividades como dramaturgo, narrador, director de cine y de teatro, periodista y guionista.

${ }^{4}$ Josefina de la Torre (Las Palmas de Gran Canaria, 1907- Madrid, 2002), perteneciente a la Generación del 27, destacó sobre todo por su poesía y por su actividad como actriz.
El origen de este proyecto editorial se halla en los problemas pecuniarios que la familia de la Torre sufrió durante la guerra. La crisis económica afectó a la fortuna familiar, obtenida en gran medida gracias al comercio, actividad a la que se dedicaba el padre de Claudio y Josefina, Bernardo de la Torre y Comminges 5 . Ante esta situación, ambos hermanos, junto con Mercedes Ballesteros, fundan en Las Palmas de Gran Canaria " "La Novela Ideal", colección dedicada a la novela rosa y policiaca. El éxito de estas colecciones que se vendían en quioscos callejeros, su lugar de venta predilecto junto con "el garito en portales y los quioscos de estación" (Díez Borque, 1972: 136), les sugiere unos rápidos beneficios. Por eso, en el número uno de la colección, City Hotel (1938), ya se explicita que el objetivo principal de esta consiste en publicar obras destinadas al ocio de los lectores (Ballesteros, 1938: 2):

La Novela Ideal, que se presenta hoy a los lectores, aspira a ser una publicación popular. Funda su aspiración en el más escrupuloso criterio que la ha de regir al seleccionar sus novelas. Estas se dirigen, sobre todo, a ese extenso mundo de lectores, ávido de agradable solaz, de amena y fácil lectura, que, en la ajetreada actividad de nuestra vida nacional, no siempre encuentra a mano el libro interesante y económico, de cómodo formato, además, con que entretener el ocio fugaz de cada día.

En "La Novela Ideal", Mercedes Ballesteros publica tres novelas policiacas: la ya mencionada City Hotel, París-Niza (1939) y El cofre de las piedras azules (1940), todas ellas con el pseudónimo de Rocq Morris. No obstante, Ballesteros se planteó también la publicación de una novela titulada El misterio del doctor Jung, que hubiera ocupado el número 14 de la colección. Así se deduce del comienzo del octavo libro de la colección, Alarma en el Distrito Sur, donde, en la lista en la que se indican los prime-

${ }^{5}$ Reverón Alfonso indica que de este apellido también existe la variante Cominges (2007: 42), más utilizada (figura, según él, en el acta de bautismo de Claudio de la Torre).

${ }^{6}$ A pesar de ser fundada en Las Palmas de Gran Canaria, a partir de 1939, tras el fin de la Guerra Civil, las narraciones de "La Novela Ideal" se publicarán en Madrid, en la imprenta de Gráficas Uguina.

UNED. REI, 7 (2019), pp. 261-289

ISSN 2340-9029 
ros quince números (Torre, 1939: 1), aparece este título que, sin embargo, nunca se publicó.

De un modo significativo, Ballesteros emplea para sus novelas rosas un pseudónimo femenino, Sylvia Visconti, que, como señala Charlo (2001: 228), en nada se parece a su nombre real. Bajo esta firma publica en "La Novela Ideal" estas doce obras: Mi marido es usted (1938), La extraña boda de Glori Dunn (1939), La aventura de una chica audaz (1939), Una mujer de veinte años (1939), El pecado de ser guapa (1940), El viaje de Diana Lynn (1940), María Elena. Ingeniero de caminos (1940), ¿Quiere usted ser mi viuda? (1940), El rapto de Valentina (1941), La telefonista del Gran Hotel (1941), Despedida de soltera (1943) y No te vayas (1944) ${ }^{7}$. El uso en ellas de un nombre femenino supone una diferencia notable respecto a la decisión tomada por Josefina de la Torre, quien emplea tanto para sus novelas rosas como para las policiacas el mismo pseudónimo: Laura de Cominges. Al elegir el nombre de una mujer en sus narraciones policiacas reivindicaba la autoría femenina de estas novelas, algo poco frecuente en el ámbito de la literatura popular. En estos años, el nombre de una mujer en la portada se asociaba más a una narrativa de carácter sentimental, sobre todo si, como ocurre en este caso, bajo esa misma firma también se habían publicado novelas rosas. No obstante, con este pseudónimo Josefina de la Torre publica tres novelas policiacas en "La Novela Ideal": El enigma de los ojos grises (1938), Alarma en el Distrito Sur (1939) y Villa del Mar (1941).

También otras mujeres colaboraron con novelas policiacas en esta colección: María Teresa Largo, pseudónimo de María Teresa Sánchez Rodríguez (Charlo, 2005: 239), publica ¿Inocente? (1944), y Consuelo Sáenz de la Calzada, manteniendo el nombre femenino de Consuelo de la Calza$\mathrm{da}^{8}$, Un muerto en la casa gris (1942). Su hermano, el pintor, actor y poeta Luis Sáenz de la Calzada, bajo el pseudónimo de Luis Marco, participa con dos novelas del mismo subgénero: El pájaro y el reloj (1941) y La carta cifrada (1943). Otro autor, Rafael García Valdés - firmando con la inicial

${ }^{7}$ Fuera de esta colección, también como Sylvia Visconti, publica Me acuerdo de Arturo en 1945.

${ }^{8}$ Con el pseudónimo de C. U. Pagate, esta autora había publicado otra novela policiaca en la editorial Moret: Un muerto en la cancha (1939).

UNED. REI, 7 (2019), pp. 261-289 de su nombre de pila-, publica Por unos ojos (1942). Con la firma de E. Berna se editan El secreto de Eduardo (1941) y La sonata encantada (1942); y, con la de Enrique de Silva, John Doorlay reaparece (1941), El visitante misterioso (1942) y Un fantasma en el siglo XX (1943). No obstante, como bien señala Vázquez de Parga, la mayoría de estos autores no "llegaron a profesionalizarse como escritores de novela popular" (2000: 33). Con la excepción de María Teresa Largo, que cuenta con una amplia producción de novela rosa, la publicación de narraciones de quiosco quedó limitada, para muchos de ellos, a "La Novela Ideal".

Ventura Doreste, al hablar de Claudio de la Torre, alude a su relación con la narrativa criminal: "Suele no decirse que este autor se dedicó también a la novela policíaca, durante su estadía en la ciudad natal, al concluir la Guerra Civil española” (1997:178). Aunque aquí sugiere que escribió novela policiaca, no queda constancia de ello ${ }^{9}$. Todo indica que sus labores en esta colección se limitaron a las de editor y corrector de estilo, tal como afirma Reverón Alfonso (2007: 219). No obstante, sí se advierte que Claudio de la Torre pensó en colaborar con una novela titulada $A$ las once de la noche - quizás policiaca-, que nunca se publicó. Al comienzo de Alarma en el Distrito Sur, donde aparece la lista ya mencionada anunciando los primeros quince números de la colección Torre, 1939: 1), figura este título con Alberto Alares como autor. El nombre, en principio desconocido, constituye el pseudónimo con el que Claudio de la Torre pensaba debutar como escritor en "La Novela Ideal".

Eliseo Izquierdo explica que Claudio de la Torre, durante su juventud, usó en ocasiones el pseudónimo de Eduardo Alar, "que tomó del título de la novela [homónima] de su tío abuelo Agustín Millares Torres, publicada en 1871" (2019: 184). Más tarde, en 1940, Claudio de la Torre firma como Alberto Alar el guion de la película Rápteme usted. Bajo este pseudónimo, sin ninguna duda, se esconde el autor, tal como prueba el hecho de que, cuando se estrena en España la obra teatral Una mujer entre

${ }^{9}$ Claudio de la Torre sí escribió una obra teatral de este subgénero, El río que nace en junio (1955). También las películas Rápteme usted (1940) - con guion suyo-, Misterio en la marisma (1943) - dirigida y escrita por él-y Dora la espía (1943) - en cuyo guion colaboró- guardan relación con el género policiaco.

UNED. REI, 7 (2019), pp. 261-289

ISSN 2340-9029 
los brazos, los periódicos anuncian que Josefina de la Torre y Alberto Alar han realizado la traducción a partir del texto original de Rafael Matarazzo (Marqueríe, 1945: 27). Reverón Alfonso, sin caer en la cuenta de que tras ese pseudónimo se oculta Claudio de la Torre, no entiende por qué en esta ocasión se ha silenciado su nombre cuando él participó en esa obra (2007: 241). Por ello, dadas las evidentes similitudes que existen entre los falsos apellidos Alares y Alar, el anuncio de la novela A las once de la noche demuestra que Claudio de la Torre pensó en algún momento publicar una obra en la colección.

Tras el fin de "La Novela Ideal", tanto Mercedes Ballesteros como Josefina de la Torre participarán con una novela en la nueva colección "Inventos, Viajes, Misterios, Aventuras", de Ediciones Océano. Como explica Vázquez de Parga (2000: 33), esta editorial no contaba con originales suficientes, así que recurrió a algunos escritores de "La Novela Ideal". Josefina de la Torre colabora en ella con su cuarta y última novela policiaca, $E l \mathrm{ca}$ serón del órgano (1944), firmada también con el pseudónimo de Laura de Cominges. Del mismo modo, en esta colección aparecerá la novela Locura en la selva (1944), firmada por B. de la Torre. Tras este nombre quizás se encuentra Bernardo de la Torre Millares, hermano de Claudio y Josefina que figuró como director de "La Novela Ideal". No obstante, al compartir el mismo nombre, también puede tratarse del sobrino de Claudio, Bernardo de la Torre Barceló, quien, según Reverón Alfonso (2007: 220), escribió para "La Novela Ideal", aunque no consta su nombre en ninguna obra de la colección ${ }^{10}$. Por su parte, Ballesteros publica en Ediciones Océano su última novela policiaca, que firma como Rocq Morris: Cena siniestra (1944).

${ }^{10}$ Dado que Reverón Alfonso (2007: 220) afirma que Bernardo de la Torre Barceló terminó su primera novela en 1941, existe la posibilidad de que este empleara el pseudónimo de E. Berna, que figura en El secreto de Eduardo, publicada precisamente ese año. Así lo sugiere la equivalencia entre la primera mitad del nombre de Bernardo y el apellido Berna.

UNED. REI, 7 (2019), pp. 261-289

\section{Lo extranjero, lo lujoso y el amor: la evasión en la novela poli- ciaca de quiosco}

La notable proliferación de las novelas de quiosco a finales de la Guerra Civil española y, sobre todo, en la década de 1940 surge gracias a la elevada demanda de una literatura de evasión. Las duras condiciones en que vivía la población durante los primeros años del franquismo, "en un país [...] sometido a durísimas condiciones materiales (son los años del hambre), y con el trauma de una reciente guerra y un clima político opresivo" (Eguidazu, 2008: 20), refuerza la búsqueda por parte de los lectores de un entretenimiento ocioso. Esta demanda constante provoca que los escritores que trabajan en estas colecciones populares no dispongan del tiempo suficiente para desarrollar tramas o personajes complejos. Bajo unas precarias condiciones laborales, acompañadas a menudo de una "escasa remuneración" (Colmeiro, 1994: 138), abandonan las pretensiones artísticas para llenar el mercado con narraciones de consumo rápido. Por ello, el objetivo fundamental de "La Novela Ideal", al que se suman otras colecciones dedicadas a la narrativa criminal como "Biblioteca Oro" (Editorial Molino), "Serie Wallace" (Editorial Cisne), "Colección Misterio" (Editorial Clíper) y "Biblioteca Iris" (Editorial Bruguera) (Sánchez Zapatero/ Martín Escribá, 2011: 99), consiste en ofrecer lecturas de ocio que favorezcan la evasión. Los editores de "La Novela Ideal" conocen bien este problem, y en los anuncios que realizan de diversas narraciones se aprecia esta preocupación. Para mantener precios modestos y llegar a un público lo más amplio posible, recurren a ediciones baratas que justifican del siguiente modo (Ballesteros, 1938: 2):

Si su apariencia es hoy sencilla, de acuerdo con los actuales y gloriosos momentos por que atraviesa nuestra España, enemigos del lujo innecesario, "La Novela Ideal", con su contenido, confiamos que llene, en cambio, los gustos más exigentes en esta clase de publicaciones.

Para atraer a estos lectores, los pseudónimos desempeñan un papel fundamental. El empleo de falsos nombres extranjero, o al menos poco frecuentes en españo, al firmar las obras respondía a la necesidad de "dar verosimilitud a unas historias protagonizadas por extranjeros y en el ex- 
tranjero" (Martín Escribá/ Sánchez Zapatero, 2011: 99). Además, como explica Charlo, el uso de estos nombres responde a un deseo de esconder la verdadera identidad: a veces, para ocultar el género, como evidencia el pseudónimo de Rocq Morris, pues una firma de mujer en una novela policiaca podía suscitar prejuicios en los lectores que asociaban nombres femeninos con textos sentimentales; en otras ocasiones, para que nadie identificara al autor en un trabajo del que "no se siente orgulloso, por lo que prefiere guardar el incógnito” (Charlo, 2013: 62). Así lo sugiere también una de las declaraciones de Josefina de la Torre, quien consideraba estas novelas "solo una forma de ganarse la vida" (Mederos, 2019: 104). De este modo, la localización de las tramas en ciudades extranjeras no solo acentúa el sentimiento de evasión, sino que, además, constituye una manera de salvar la censura. Por un lado, las leyes de la dictadura prohibían que los detectives privados colaboraran en la resolución de asesinatos. Por otro, situar crímenes violentos en territorio español resultaba imposible, pues "su sola mención podía ser interpretada como una muestra de debilidad del régimen” (Martín Escribá/ Sánchez Zapatero, 2011: 99).

La mayoría de estas novelas transcurren en Inglaterra, como se aprecia en dos de las obras policiacas de Ballesteros: City Hotel y de Cena siniestra se desarrollan en Londres. Por el contrario, en París-Niza la mayor parte de la acción ocurre en París, al igual que en El cofre de las piedras azules, donde el protagonista, sin embargo, proviene de Oxford. Pero, en cualquier caso, todas estas novelas presentan un mundo aristocrático y lujoso donde los personajes pertenecen a las clases altas o incluso a la nobleza. Dados los límites impuestos por la censura, la presentación de estos grupos humanos se aleja de la crítica social, sin aludir en ningún momento a problemas relacionados con las clases sociales. Así, los autores de novela popular de estos años no adaptan los cánones de la narrativa negra, vinculada con las denuncias sociales, sino "los modelos policiacos [que] acostumbraban a presentar una sociedad exótica y alejada del país" (Sánchez Zapatero, 2006: 74). La localización en el extranjero, el alto poder adquisitivo de los personajes y el ambiente por lo general feliz en el que viven favorece la evasión. Y, por tanto, el mundo en el que se desarrolla la historia le resulta lejano al público lector.

El lujo en el que viven estos personajes se advierte en ocasiones en sus nombres, precedidos muchas veces por fórmulas de tratamiento anglosajonas que señalan su alta posición social. De esta manera, en City Hotel el narrador omnisciente se refiere al abogado protagonista como sir Edward Norton. En El cofre de las piedras azules, el también abogado Eduardo Maxwell proviene de una familia acomodada; sus padres son tratados como lord y lady Maxwell. También varios de sus amigos pertenecen a la nobleza: el conde de Greville, los archiduques de Wisilow, el vizconde Ernesto Delbert, el marqués de Haricourt y lady Davonshire se encuentran en su círculo de amistades. En Cena siniestra, a pesar del extravagante comportamiento del detective protagonista, éste se codea con miembros de la clase alta londinense, como lord y lady Gipps, lord y lady Thynne, lady Eva Verner y sir Thomas Storry. Por último, en París-Niza, si bien no se explicita ninguna relación con la nobleza, sus personajes disponen de notables riquezas: el protagonista, Fausto Brier, ha conseguido un "magnífico puesto de ingeniero jefe a los veintiséis años" (Ballesteros, 1939: 6); su tía, la inglesa Agatha Dorry, posee un "histórico palacio" (Ballesteros, 1939: 7) en la ciudad francesa de Blois; y la estadounidense Irene Moore, perseguida por unos gánsteres, heredará la fortuna de su padre, "Moore, el millonario" (Ballesteros, 1939: 79). No se aporta más información sobre este magnate, pero la persecución de su hija ofrece una idea de la inmensidad de su riqueza.

No obstante, la armonía que existe en estos mundos se perturba por los crímenes cometidos contra alguno de los miembros de estos grupos privilegiados, aunque luego el investigador siempre resuelve el caso con éxito. Estos finales, en los que se restablece el orden inicial perdido, promueven "la visión de un ambiente social armónico [...] como respuesta defensiva a la disgregación de la forma de vida de la aristocracia afianzada parasitariamente" (Resina, 1997: 20). Alejadas, por tanto, de toda representación realista de la sociedad, las novelas policiacas de quiosco recurren a una sociedad en muchos aspectos idealizada donde no se cuestiona la jerarquía social.

Pero, debido a que suceden en una comunidad en apariencia pacífica, los asesinatos producen un mayor impacto entre los conocidos de la 
víctima y en el resto de la alta sociedad. Además, estas muertes, junto con los procesos judiciales y las investigaciones que surgen en torno a ellas, generan un enorme interés en cada ciudad donde ocurren. Los periódicos publican varias noticias que recogen los hechos delictivos y los avances policiales que suscitan la curiosidad de los lectores. Si bien en muchas ocasiones tergiversan datos para señalar a algún culpable con rapidez, también exponen el éxito de los investigadores cuando consiguen resolver el caso, tal como se lee al final de París-Niza: "Fausto Brier se convirtió en el héroe de la prensa y su retrato, que había aparecido con el pie de 'asesino', lucía ahora en todos los periódicos, sonriente por el triunfo y colmado de elogios" (Ballesteros, 1939: 113). Sin embargo, los más ansiosos por conocer las últimas novedades ni siquiera esperan a la próxima publicación, sino que van a los juzgados: "Nunca, como en aquella ocasión, se amontonaron los coches y las personas alrededor del Palacio de Justicia" (Ballesteros, 1938: 83). Entre los que acuden como público se encuentra, por supuesto, el sector más rico de la ciudad: "Tres días más tarde volvió a reunirse lo más escogido de la sociedad de Londres en el Palacio de Justicia” (Ballesteros, 1944: 52).

Junto con la resolución de los asesinatos, que supone ese "orgasmo final del éxito del héroe” que, según Vázquez Montalbán (1989: 50), caracteriza esta narrativa, culmina la historia de amor que los detectives mantienen con alguna de las mujeres que se han involucrado en el caso. Este final feliz, propio de las novelas rosas, favorece del mismo modo la evasión. No solo se recupera la armonía que existía antes de los crímenes, sino que también los protagonistas - con la excepción de Robert Clay en Cena siniestra - viven una historia de amor ideal. Ninguno de los peligros a los que se han enfrentado ha impedido esa unión dichosa. City Hotel ya indica desde su subtítulo, "Novela de misterio y amor", este aspecto de la trama. En ella, tanto Edward Morton, quien resuelve el caso, como su sobrino, Alfredo Cummings - acusado del crimen y luego absuelto-, expresan su amor por dos de las mujeres relacionadas con el difunto en un baile con el que termina la novela: "A los allí presentes se les planteó un problema difícil de resolver. El problema era el siguiente: ¿quiénes estaban más enamorados: Carlota Davis y Alfredo Cummings, o Peggy Brooks y el célebre Edward Morton?” (Ballesteros, 1938: 111). Fausto Brier, en París-
Niza, acaba también enamorado de Irene Moore, la mujer a la que ha salvado de un secuestro perpetrado por gánsteres estadounidenses: "Cuando entraron los reporters, que terminan siempre por enterarse de todo, a tomar información y fotografías, encontraron a Irene Moore y a Fausto Brier besándose" (Ballesteros, 1939: 114). Por su parte, Eduardo Maxwell, en El cofre de las piedras azules, se casa con Verónica, a quien ha salvado de un proceso judicial injusto en el que se le acusaba del asesinato de su padre: "Verónica y Eduardo acababan de casarse" (Ballesteros, 1940: 97).

\section{Los investigadores de Rocq Morris: detectives aficionados y héroes de aventuras policiacas}

La literatura policiaca de masas de los años cuarenta, para llegar a un público más amplio, recurría a detectives alejados de la figura tradicional del intelectual, tal como explica Dennis Porter: "the detective fiction of pure ratiocination $[\ldots]$ has never been genuinely popular. In order to appeal to a broader public, it needed the vital admixture of action or manners, violence or satire" (1983: 163). Este modelo de detective, aunque emplea en ocasiones sus habilidades de deducción, destaca por adoptar una actitud activa en la búsqueda de pruebas que a veces implica el uso de la violencia.

La caracterización de estos detectives como héroes de aventuras resultaba compatible con el ritmo frenético de redacción que seguían los escritores de narrativa popular. Bajo una presión considerable por publicar, y sin tiempo suficiente para pensar con detenimiento en las tramas, recurren a investigadores que resuelven los crímenes gracias a sus aptitudes como aventureros que persiguen, exploran lugares sospechosos o se pelean. Se trata, en definitiva, de un investigador que remite a la novela de aventuras delictivas, que llega a España cuando "la editorial Molino publica su colección de 'Hombres Audaces', copia de los pulps norteamericanos dedicados íntegramente a la narración de aventuras criminales de personajes como La Sombra, Doc Savage [...]" (Valles Calatrava, 1991: 97). Este modelo de detective posee admirables habilidades físicas y mentales, mucha valentía y un claro sentido de la justicia. Incluso cuando no pertenece 
a ningún cuerpo policial, supera a los profesionales por este dechado de virtudes que encarna.

Los detectives de Mercedes Ballesteros presentan varios de estos rasgos, pero ninguno de ellos pertenece a los cuerpos oficiales de policía, sino al grupo de investigadores que Alemán Sainz define como "aficionados” (1975: 12). En ocasiones poseen trabajos alejados de la criminología, pero siempre muestran su espíritu detectivesco. Los intereses de los investigadores se inclinan hacia las pesquisas policiales, algo que en algunos casos se remonta hasta la infancia de los protagonistas. Eduardo Maxwell, en El cofre de las piedras azules, así lo reconoce: "Y mientras el coche recorría las solitarias calles de Neuilly fue pensando en sus aficiones policiacas que databan de su primera infancia" (Ballesteros, 1940: 11). Este mismo personaje, además, parece haber nacido para investigar crímenes, aunque se gane la vida como abogado: “¿Por qué desde pequeño había tenido tanta afición a los asuntos policiacos? Nadie había en su familia, ni lo había habido desde el siglo XVII, que se hubiese ocupado de asuntos parecidos" (Ballesteros, 1940: 42). Esta pasión por lo detectivesco convierte a Maxwell en la persona adecuada para resolver el asesinato del conde de Greville. Tras enterarse de que el día antes de morir celebró una fiesta en casa, elabora una detallada lista de los asistentes para interrogarlos, lo que revela su profesionalidad: "Se propuso escribirla por orden alfabético para hacer una investigación ordenada y perfecta” (Ballesteros, 1940: 41).

A pesar del interés que demuestra por resolver el caso, se entera de la existencia de varias evidencias por casualidad, como la del cofre de piedras azules que contiene la carta que señala al culpable. Lo encuentra, sin haberlo buscado, en una tienda de antigüedades. Su aspecto le recuerda de inmediato el del cofre que le había descrito una joven, loca en apariencia, que también casualmente se había metido en su taxi durante los primeros días de su estancia en Francia. Tras acompañarla a su habitación, ella le habla de una escena sangrienta en la que veía un cofre de piedras azules. Como luego descubrirá, esta joven, Verónica, describió la escena del asesinato de su padre, que sostenía en sus manos ese cofre. En él se escondía una nota que, de nuevo, encuentra por casualidad cuando un niño que juega con él descubre un doble fondo: "Moviendo una de las enormes piedras

azules quedaba al descubierto una especie de puerta" (Ballesteros, 1940: 88). Gracias a este papel y al análisis de las huellas dactilares que presenta, Maxwell demuestra que el vizconde Ernesto Delbert ha asesinado al conde de Greville. Este criminal planeaba casarse con la hija del difunto para, tras declararla loca, heredar su fortuna. Cuando esa nota, en la que el vizconde aludía a sus planes, cayó en manos del conde de Greville, Delbert lo asesinó para que no interfiriera en ellos. Ante estas evidencias, el prefecto de la policía agradece a Maxwell su colaboración: "Enhorabuena, amigo mío. Le doy las gracias por haberme enmendado la plana... Mucho me gusta no equivocarme. Pero más me gusta que la justicia se cumpla como debe cumplirse" (Ballesteros, 1940: 94).

También Edward Morton, el investigador de City Hotel, ejerce la abogacía. Tanto él como Eduardo Maxwell, al compartir este oficio, guardan cierta relación con el mundo del crimen y de la justicia. Pero, a pesar de ello, en varias ocasiones los narradores omniscientes resaltan su desvinculación de los cuerpos de policía oficiales, tal como se aprecia en esta cita sobre Eduardo Maxwell: "Una idea sin fundamento cruzó por su cerebro de detective amateur" (Ballesteros, 1940: 13). No obstante, este carácter de aficionado no influye en su prestigio. Al contrario, algunos policías, conocedores de su talento, se enorgullecen de colaborar en sus pesquisas para descubrir al verdadero criminal, como se advierte cuando Maxwell le pide al agente Henry que colabore con él: "M. Henry, que era un policía cien por cien, estaba encantado de desempeñar un papel misterioso y novelesco. Había tomado a Maxwell por un famoso detective americano" (Ballesteros, 1940: 92).

También Morton ha conseguido la fama en Londres gracias a los crímenes que ha resuelto como detective, no a su labor como abogado. En su caso, al igual que Sherlock Holmes, cuenta además con un ayudante: Anthony, su criado, colabora con él en sus investigaciones y le aclara las ideas. El propio Morton reconoce que su ayuda resulta indispensable, pues sabe que sin Anthony no habría obtenido tanto prestigio por su trabajo: "Y en verdad que su criado era a la vez un apreciable colaborador en todos los asuntos delicados. Su cerebro vulgar descubría, o inducía a descubrir a veces, detalles o coincidencias que inteligencias más cultivadas dejaban 
escapar" (Ballesteros, 1938: 7). El caso al que se enfrenta en City Hotel, la muerte del famoso violinista Richard Brooks, pone a prueba sus habilidades como detective y como abogado, pues asume la defensa de su sobrino, Alfredo, en el juicio en el que, con pruebas mal interpretadas, se le acusa de ese asesinato.

Los policías de Scotland Yard que trabajan en el caso, Powell y Charles Wast, esperan que Morton fracase como abogado. Envidiosos de sus éxitos, desean que todos observen los errores que suponen que cometerá, y así lo expresa Wast: "Estaba ya harto de la infalibilidad de Morton. Me cargan estos tipos que siempre aciertan, que todo les sale bien. Acaban por darse en la cabeza. Esto le servirá para bajar los humos" (Ballesteros, 1938: 75). Sin embargo, la superioridad del detective aficionado frente a los investigadores oficiales queda acreditada durante el juicio, donde Morton exhibe las pruebas que ha reunido para exculpar a su sobrino y descubrir al verdadero culpable.

En esta recopilación de evidencias Morton cuenta con la ayuda de Anthony. Siguiendo instrucciones del abogado, este criado sigue a Peggy, una mujer que posee información relevante sobre el caso (Ballesteros, 1938: 40), acude en busca de cartas personales a casa de Alfredo (Ballesteros, 1938: 81) e incluso analiza junto con Morton la escena del crimen: "Sería demasiado largo de escribir el detallado examen efectuado por ambos hombres desde las diez de la noche hasta las seis de la mañana siguiente. No quedó mueble por remover, cortina por desplegar, cerradura por ser probada..." (Ballesteros, 1938: 97). Con las evidencias que ha recogido y basándose también en varios testimonios, Morton señala a Cecilia Bell como la culpable: despechada por la indiferencia con que Brooks, su antiguo amante, le había tratado, le disparó una noche sembrando determinados indicios que levantaran falsas sospechas contra Alfredo, su exnovio. El éxito de sus investigaciones se debe a la profesionalidad con la que han realizado las pesquisas, superando la eficacia de las actuaciones policiales.

Los riesgos que corren estos detectives suponen muchas veces un grave peligro para sus vidas, aunque esto no les detiene. Faustro Brier, el investigador de París-Niza, muestra un claro carácter aventurero, más intenso que el de los detectives anteriores. Sin embargo, él no guarda nin- guna relación profesional con el mundo de la criminología; trabaja como ingeniero. De hecho, su vinculación con el caso que resuelve surge de una casualidad: conduciendo por la carretera que une Niza y París, se encuentra con una extraña escena en la que unos gánsteres amenazan a una joven, Irene Moore, y a su acompañante, Jean Hervier. Brier, exhibiendo su valentía, pone en riesgo su vida para defenderlos (Ballesteros, 1939: 9):

La actuación de Fausto fue rápida y eficaz. Bajó de su coche de un salto y asestó tan fuerte puñetazo en el brazo al poseedor de la pistola que el arma cayó al suelo. Una vez con la pistola en su poder, amenazó al bandido. Ni una palabra salió de sus labios. Los hechos eran bastante expresivos. El desconocido montó en el coche, que se puso en marcha enseguida. Por la imaginación de Fausto pasó la idea de seguirlo, pero ¿cómo iba a abandonar a aquella infeliz pareja, ella muerta de susto y él, mal herido [sic]? Sonó una detonación. Habían disparado del coche fugitivo. Fausto devolvió el disparo y, luego, lanzó un leve quejido. La bala había rozado su brazo izquierdo.

Aunque Brier les salva, la muerte posterior del financiero M. Chatelain provoca que, sin pruebas suficientes, la policía le acuse de ese asesinato y le encarcele hasta la celebración del juicio. Sin embargo, mostrando una vez más su astucia, escapa de prisión para descubrir al verdadero culpable de ese delito. Con la ayuda de uno de los guardianes de la prisión, que también participa en su huida, averigua que Michael Curson, su antiguo jefe en la fábrica en la que trabajaba, ha cometido el crimen. La colaboración del guardián en esta tarea, aunque no se detalla, equivale a la de un investigador ayudante, pues Brier le considera "una especie de Sherlock Holmes" (Ballesteros, 1939: 111).

Para atrapar al criminal, Brier se adelanta de algún modo a los planes de los gánsteres, entre los que se encuentra Jean Hervier, que ha ocultado su verdadera identidad para convertirse en amigo de Irene y seguir de cerca sus pasos. Cuando la secuestran al retenerla en un coche, la joven descubre con sorpresa que Fausto Brier lo conduce. El gánster que acompaña en el asiento trasero a Irene, Michael Curson, tampoco sale de su asombro, pues eso significa que su plan ha fracasado. El joven ingeniero le 
detiene y lo lleva ante la justicia. Entonces, Fausto asegura al juez que Curson no solo colaboraba en el secuestro, sino que también ha asesinado a una mujer, Martha Gwen, que poseía información que le hubiera delatado. Sin embargo, la autora demuestra que no ha dispuesto del tiempo necesario para elaborar una justificación detallada de la culpabilidad de Curson, pues Brier afirma que posee evidencias de ello sin mencionarlas: "Tengo pruebas que harían muy largo mi relato" (Ballesteros, 1939: 112). Brier ha triunfado y ha desenmascarado al culpable, pero lo ha conseguido tras haberse saltado las leyes que lo han encarcelado. Representa, por tanto, un tipo de detective que, según Martín Cerezo, "distingue inequívocamente entre la justicia de los hombres, codificada en leyes, y la idea de justicia, que atiende a una noción ideológico-moral" (2006: 59).

\subsection{Robert Clay, un detective paródico}

De los investigadores creados por Ballesteros, Robert Clay, el protagonista de Cena siniestra, resulta el más peculiar de todos, y por ello merece un análisis más detenido que el resto. Además, fue el único sobre el que la escritora pensó crear una serie literaria que, sin embargo, jamás continuó. Así se indica al final del libro de El caserón del órgano, donde se publicita esa entrega de la siguiente manera: "Cena siniestra. Este es el título del primer episodio de la serie "Hazañas de Robert Clay" Torre, 1944: 72). También al comienzo se informa de modo similar de esta nueva publicación: “Hazañas de Robert Clay’. Este es el título general de la serie de aventuras del más original de los detectives modernos, creado por Rocq Morris" Torre, 1944: 1). Incluso la portada indica que forma parte de esta serie de hazañas. Estos anuncios han podido confundir a estudiosos como Vázquez de Parga (1993: 100), quien sugiere que Robert Clay protagoniza las cuatro novelas policiacas publicadas bajo el nombre de Rocq Morris. Este autor afirma incluso que "Rocq Morris inauguró precisamente 'La Novela Ideal' presentando al detective londinense Robert Clay" (Vázquez de Parga, 1993: 100), cuando en esa primera obra, City Hotel, no se menciona en ninguna ocasión a este detective. Por tanto, supone un error citarlo como uno de los ejemplos de "policías repetitivos" (Vázquez de Parga,
2000: 113) creados por los escritores populares de este periodo. En realidad, este investigador solo interviene en Cena siniestra.

Robert Clay se diferencia del resto de detectives de las novelas de Ballesteros por su carácter paródico. Esto revela que las narraciones policiacas ya formaban parte del imaginario colectivo en la sociedad española de la primera mitad del siglo XX, pues, tal como explica Rivero Grandoso, los "códigos parodiados debían ser reconocidos por un público amplio para que el humor fuera entendido" (2016: 46). El investigador aficionado Robert Clay, al igual que el también paródico Agapito Bermúdez creado por Joaquín Belda, supone en gran medida una parodia de Sherlock Holmes. Sánchez Zapatero (2017: 45), al analizar el influjo del personaje de Conan Doyle en ¿Quién disparó? (1909) ${ }^{11}$, determina que el detective de Belda muestra numerosas relaciones intertextuales con Holmes, como su afición a tocar un instrumento musical (la guitarra), el uso de expresiones anglosajonas y el hecho de contar con un ayudante que le acompaña en sus pesquisas. Del mismo modo, Robert Clay, londinense, expresa inquietudes artísticas, en su caso como pintor, y también cuenta con la ayuda de su criado, Brent, quien colabora con él en sus investigaciones: "Brent no sólo era un criado, $[\ldots]$ sino el auxiliar impagable de Robert en todo asunto policíaco" (Ballesteros, 1944: 13).

La aparente indiferencia de Clay ante los crímenes y su fingida torpeza no suponen ningún problema para resolver con éxito los casos. Al contrario, con ellas despista tanto a los que confían en sus capacidades como a los que no lo toman en serio por sus continuas bromas y ocurrencias. Ninguna de sus extravagancias ha mermado su prestigio. De hecho, al comienzo de Cena siniestra varios personajes, invitados por lord y lady Gipps a cenar en su casa, hablan sobre los éxitos de este detective aficionado. Aunque Clay se define a sí mismo como pintor, su fama la debe a los delitos que ha resuelto. La mayoría de estos invitados elogian sus habilidades detectivescas, superiores según ellos a las de los policías oficiales: "También tiene la 'pose' de ser sólo un detective amateur, pero encuentra

${ }^{11}$ Joan Ramon Resina considera que ¿Quién disparó? constituye un ejemplo de "novela bufa que aprovecha aspectos de la novela policiaca" (1997: 27), y no de una parodia.

UNED. REI, 7 (2019), pp. 261-289

ISSN 2340-9029 
a los culpables mucho antes que la gente de Scotland Yard" (Ballesteros, 1944: 6). Insisten en que varios casos en los que colaboró habrían acabado con el triunfo de los delincuentes "si no es por su intervención" (Ballesteros, 1944: 6).

Precisamente un hecho que se produce antes de esta misma cena origina la situación perfecta para que Clay muestre su talento como investigador. Antes de ella, los invitados reciben una nota anónima en la que se anuncia una muerte durante esa reunión, y varios de ellos, asustados, rechazan la invitación. Sin embargo, a pesar de lo que sugiere el título y la ilustración de la portada, en la que una figura tenebrosa y con aparentes manchas de sangre se abalanza sobre un hombre y dos mujeres que cenan vestidos de gala, la novela no pertenece al subgénero del terror. Lo siniestro, en este caso, se manifiesta en la posterior muerte de Fred Gipps, el dueño de la casa. Al día siguiente de la cena se descubre el cadáver en su cuarto.

La complejidad de este caso se acrecienta al tratarse de un asesinato cometido, en principio, en una habitación cerrada, como declara la esposa de Fred: "Cuando ustedes se marcharon, Fred entró en su cuarto y cerró con llave, como tenía por costumbre. Ha sido necesario descerrajar la puerta para entrar esta mañana" (Ballesteros, 1944: 10). Analizando la habitación donde se encontró el cuerpo, Clay toma la última copa de la que bebió Fred, en la que aún queda un "extraño sedimento" (Ballesteros, 1944: 10), pero se le cae, le mancha la ropa y se rompe contra el suelo. David Tennant, amigo de la viuda, presiona a Clay para que convenza a esta mujer de que llame a la policía. Sin embargo, el detective no expresa el menor interés por el presunto asesinato, incluso afirma que no comprende a los que se preocupan por conocer la verdad: " $i$ Siempre la gente empeñada en saber los porqués de las cosas! ¡No puedo con esta tremenda curiosidad!" (Ballesteros, 1944: 13). Cuando se descubre que Fred había pensado en cambiar su testamento ante notario, todas las sospechas recaen sobre sus familiares cercanos.

Clay, a diferencia de otros investigadores de las novelas de Rocq Morris - como Fausto Brier-, se aleja del modelo heroico de detective. La búsqueda de pruebas, aunque la realiza con ingenio y discreción, no requiere ningún tipo de violencia. Sus dotes de observación le bastan para descubrir detalles relevantes, como la similitud que existe entre un broche que lleva Olivia Gipps y Zoe Taitokis, una mujer de la alta sociedad de visita en Londres (Ballesteros, 1944: 8). De hecho, su aguda observación le aporta una importante suma de dinero en las carreras de caballos al apostar por el animal ganador (Ballesteros, 1944: 23).

No obstante, la extravagancia de Clay produce rechazo en los policías oficiales, quienes no comprenden su manera de proceder. Sheridan, investigador de Scotland Yard encargado del mismo caso, lo desacredita como detective por su comportamiento y sus comentarios: "Habla usted como un profano" (Ballesteros, 1944: 18). El propio Clay reconoce su extraño proceso de investigación al pedirle a Herbert Gold, amigo de los Gipps, que se olvide de la mujer que, en apariencia, ama, Patricia Lister, porque él también siente algo por ella: "Puede que encuentres mi manera de proceder poco corriente; pero es que yo he nacido cansado de las maneras de proceder corrientes" (Ballesteros, 1944: 56).

Pero, a pesar de estas consideraciones, Clay muestra más eficacia como detective que los policías, sobre todo tras el asesinato de Ronald Graham, amigo de Fred Gipps. Todo indica que Olivia lo ha asesinado al visitarlo en su despacho y que ella misma advierte del asesinato al portero de su vivienda para despistar. Este trabajador confirma que ella subió a la vivienda de Graham poco después de que este hubiera recibido a un agente de seguros. Y, aunque la policía encarcela a Olivia, Clay realiza pesquisas mucho más efectivas. Visita al criado de Graham, Alike, de origen malayo, y le contrata con la única condición de que cocine comida de su país (Ballesteros, 1944: 42). Así, descubre que las misteriosas cartas que se habían repartido entre los invitados a la cena en casa de los Gipps formaban parte de una broma de mal gusto de Graham. Alike, siguiendo órdenes, las repartió, pero no guardan ninguna relación con los crímenes.

En realidad, solo existe un culpable en los asesinatos de Fred Gipps y de Ronald Graham. Clay lo demuestra en el juicio, donde agota la paciencia del juez con explicaciones que se desvían del objeto de la acusación: "El presidente volvió a llamar la atención a Clay. Se estaba saliendo absolutamente del tema. No contestaba a las preguntas que se le hacían y 
todo parecía que trataba de burlarse del tribunal" (Ballesteros, 1944: 61). Entre bromas y comentarios un tanto jocosos, Clay revela el porqué de muchas de sus acciones. Sus fingidas muestras de torpeza formaban parte de la investigación. La caída sobre su ropa de la última copa de la que bebió Fred Gipps antes de morir no fue casual. Gracias a ella descubrió que esta contenía veneno, tal como ha revelado su análisis químico: “[...] en el laboratorio, le dijeron a Brent que el líquido que había caído sobre la rodilla de mi pantalón contenía arsénico" (Ballesteros, 1944: 61).

Del mismo modo, había planeado con cuidado la exposición de varios de sus cuadros, inaugurada horas antes de su testimonio en el juicio. Entre los retratos que ahí se exhiben, que reflejan a varios de sus amigos y conocidos, el portero de la vivienda de Ronald Graham reconoce en el cuadro que representa a Herbert Gold al agente de seguros que visitó a este amigo de Fred Gipps el día en que lo asesinaron. Con esta prueba, Clay aclara que el verdadero asesino es Herbert y no Olivia. Cuando este supo que Graham había conseguido una carta de amor que él le había escrito a Olivia, le visitó para exigirle que se la entregara. Herbert pensaba que, si salía a la luz, se descubriría que él había envenado a Fred Gipps por celos. Pero, como Graham se negó, lo asesinó.

A estas conclusiones ha llegado gracias a la información que aparece en esa carta, en la que Herbert acusa a Olivia "de coqueta, de haber jugado con él, de haber roto su vida" después de haberle dicho que "adoraba a su marido y que no podía querer a ningún otro hombre" (Ballesteros, 1944: 62). Para no despertar sospechas, tomó el veneno que escondía el broche de Olivia. Sabía que en esa joya lo encontraría porque era igual que el de Zoe Taitokis, que también contenía arsénico. Al examinarlo entre sus manos, puso con facilidad el veneno en la copa. Para desviar las sospechas de la policía hacia él, Herbert fingió que estaba enamorado de Patricia Lister. Y, en gran medida, esta estrategia le funcionó. Por eso, Clay termina su explicación del caso con una afirmación que revela su visión de los cuerpos policiales, a los que él supera en profesionalidad a pesar de sus extravagancias: “¡Nada hay tan fácil como engañar a la policía!” (Ballesteros, 1944: 63).

Robert Clay no termina enamorado de ninguna mujer. La ausencia de un desenlace romántico responde a la peculiar personalidad del detective, que elude los compromisos matrimoniales. En varias ocasiones la obra refleja su carácter un tanto mujeriego, pues aprovecha cualquier oportunidad para intentar seducir a diferentes mujeres, tal como le recuerda su tía Eva Verner: “¡Cuidado con lo que bebes y con lo que haces! Acuérdate del año pasado cuando, aquí mismo, te declaraste a mi sobrina Emily a las tres de la madrugada, me pediste su mano a las tres y media y al día siguiente no te acordabas de nada" (Ballesteros, 1944: 14). Incluso su afirmación de que está enamorado de Patricia Lister forma parte de su investigación: la reacción de Herbert Gold al escucharla le aportará información relevante sobre si el sospechoso guarda sinceros sentimientos de amor hacia ella. Clay, en realidad, no siente nada por esta mujer. Así, el detective se erige como un soltero empedernido que no expresa ninguna preocupación por encontrar una mujer con la que casarse.

\section{Conclusiones}

Las novelas policiacas que Mercedes Ballesteros firmó como Rocq Morris demuestran que la autora conocía bien los tópicos del subgénero y los reprodujo para satisfacer las exigencias del público de comienzos de la posguerra. En un ambiente marcado por el lujo que favorece una lectura de evasión, los detectives actúan en ocasiones como héroes de aventuras y resuelven los casos gracia a su astucia y a la búsqueda activa de pruebas. La resolución exitosa de los crímenes les aporta no solo un gran prestigio, sino también la oportunidad de vivir un amor pleno junto con alguna de las mujeres involucradas en ellos. No obstante, las diferencias que presentan entre sí estas novelas requieren una clasificación distinta para algunas de ellas.

City Hotel, El cofre de las piedras azules y Cena siniestra constituyen ejemplos de novela enigma, definida por Rivero Grandoso como el "tipo de novela criminal en el que el principal interés radica en el desvelamiento del autor del asesinato" (2016: 534). Se trata, además, del modelo policia- 
co que, según Valles Calatrava (1991: 106), predominaba en esta época en España. Ninguno de los detectives de estas obras recurre a complejas cuestiones intelectuales o culturales, como "las trayectorias posibles de una bala de pistola o las costumbres de los animales exóticos reducidos a la cautividad" (Vázquez de Parga, 2000: 46), para explicar cómo se realizaron los asesinatos. La rapidez en la escritura que exige una colección de quiosco no permite la elaboración de explicaciones muy detalladas a los crímenes. Sin embargo, sus conclusiones se obtienen gracias a las evidencias aportadas por diversas pruebas que los propios detectives han recogido o que han encontrado por casualidad. Así, la solución del caso surge de la cuidadosa investigación que han llevado a cabo, que contrasta con las actuaciones precipitadas de la policía. El análisis de pruebas y la lógica señalan al culpable.

No obstante, este proceso de investigación, aunque también existe en París-Niza, apenas se describe en esta narración. A diferencia de las anteriores, esta constituye una novela de aventuras policiacas por la ausencia de un análisis detallado de los hechos y por el carácter heroico del protagonista. En el resto de obras criminales de Ballesteros existe una recopilación de evidencias que señalan a los verdaderos delincuentes, pero en París-Niza no se relata ningún procedimiento de investigación. Ni siquiera el detective aficionado muestra pruebas concretas al juez que demuestran la culpabilidad del criminal. El encargado de este caso, el ingeniero Fausto Brier, lucha contra las leyes que le han encarcelado y, con un claro sentido de la justicia, se enfrenta a los gánsteres que planifican el secuestro de la joven millonaria Irene Moore. Se ha comportado como un héroe y, desde luego, ha llevado a cabo una investigación que delata a los criminales. Pero nada de ella se describe a los lectores, que solo asisten a las aventuras a las que se enfrenta para salvar a Moore y detener a los mafiosos.

Asimismo, Cena siniestra cuenta con un detective que supone un alejamiento considerable de los estereotipos encarnados por Edward Morton, Fausto Brier y Eduardo Maxwell. El pintor Robert Clay, aficionado a la resolución de crímenes, ofrece una parodia de la figura del detective que remite al también paródico Agapito Bermúdez creado por Joaquín Belda. Sin embargo, Clay no abandona muchas de las características de los otros investigadores de Ballesteros. Al igual que el resto, posee un talento superior al de la policía y su método de trabajo también se basa en la recopilación de evidencias. No obstante, la mayor diferencia radica en la manera en la que obtiene esas pruebas que señalan al culpable y en su carácter excéntrico. Nadie comprende su comportamiento, ni los personajes que le rodean ni los lectores, hasta que al final se revela el sentido de sus actuaciones. Sus constantes bromas, si bien forman parte de su personalidad, provocan que sus pesquisas no levanten sospechas entre los delincuentes ni entre los agentes oficiales, que desconfían de él hasta que corroboran su eficacia. Por tanto, aunque representa un modelo detective no demasiado frecuente en la literatura de quiosco de esos años, tampoco supone ninguna innovación literaria.

Por todo ello, el análisis de estas obras manifiesta la necesidad de incluir la narrativa popular en los estudios literarios para configurar un canon alternativo al que ha imperado hasta hoy. Aunque estas novelas no persiguen altas pretensiones literarias, sino más bien rápidos beneficios económicos, su incorporación al ámbito filológico dará lugar a avances significativos en el conocimiento de la producción novelística española del siglo XX. Por un lado, con ello se obtendrá una visión más completa de la narrativa de este periodo. $Y$, por otro, se conseguirá una imagen más precisa de diversos autores que, trabajando en distintos géneros, son recordados solo por alguna de sus facetas como escritores. Así ocurre con Mercedes Ballesteros, conocida por su teatro y por sus novelas breves, ya de por sí poco estudiadas.

Sin embargo, su narrativa policiaca de quiosco, a pesar del olvido en el que ha caído, la convierte, junto con Josefina de la Torre, en una de las primeras mujeres que se dedicaron a este subgénero durante el franquismo. Si bien Ballesteros, como el resto de autores de novela popular en estos años, imita modelos extranjeros y evita el tratamiento de problemas propios del país, cumple el objetivo que se propuso en estas narraciones: poner a disposición del público una historia entretenida y ofrecer una distracción. Se trata, desde luego, de un objetivo alejado de grandes ambiciones literarias. Pero no por ello merecen estas obras el desdén por parte de 
la crítica, pues su estudio contribuye a un conocimiento más profundo de la labor literaria de Mercedes Ballesteros.

\section{Recibido: $14 / 08 / 2019$}

Aceptado: 10/11/2019

\section{Referencias bibliográficas}

“Bodas recientes” (1933), Blanco y Negro, 2.169 [8 de enero], pp. 72-73.

Alemán Sainz, Francisco (1975), Las literaturas de kiosko, Barcelona: Editorial Planeta.

Ballesteros, Mercedes (1938), City Hotel, Las Palmas de Gran Canaria: Diario de Las Palmas.

--- (1939), París-Niza, Las Palmas de Gran Canaria: Diario de Las Palmas.

--- (1940), El cofre de las piedras azules, Madrid: Gráficas Uguina.

--- (1944), Cena siniestra, Madrid: Ediciones Océano.

Charlo Ortiz-Repiso, Ramón (2001), “La novela sentimental”, en Fernando Martínez de la Hidalga et al. (eds.), La novela popular en España 2, Madrid: Ediciones Robel, pp. 177-232.

--- (2005), Autores y seudónimos en la novela popular, Sevilla: Padilla Libros Editores y Libreros.

--- (2013), La novela popular en España, Sevilla: Secretariado de Publicaciones de la Universidad de Sevilla.

Colmeiro, José F. (1994), La novela policiaca española: teoría e historia crítica, Barcelona: Anthropos.

Díez Borque, José María (1972), Literatura y cultura de masas. Estudio de la novela subliteraria, Madrid: Al-Borak.

Doreste, Ventura (1997), Ensayos insulares, Santa Cruz de Tenerife: Nuestro Arte.
Eguidazu, Fernando (2008), Del folletín al bolsilibro. 50 años de novela popular española (1900-1950), Guadalajara: Silente.

Fernández Gutiérrez, José María (2004), La Novela del Sábado (19531955). Catálogo y contexto histórico literario, Madrid: Consejo Superior de Investigaciones Científicas.

Godsland, Shelley (2007), Killing Carmens. Women's Crime Fiction from Spain, Wiltshire: University of Wales Press.

Izquierdo, Eliseo (2019), Encubrimientos de la identidad en Canarias. Seudónimos y otros escondrijos en la literatura, el periodismo y las artes en $\mathrm{Ca}$ narias, Tomo I, San Cristóbal de La Laguna: Instituto de Estudios Canarios.

Marqueríe, Alfredo (1945), “Calderón: Estreno de Una mujer en los brazos, original de Rafael Matarazzo, traducida por Josefina de la Torre y Alberto Alar", $A B C$ [23 de noviembre], p. 27.

Martín Cerezo, Iván (2006), Poética del relato policiaco (de Edgar Allan Poe a Raymond Chandler), Murcia: Servicio de Publicaciones de la Universidad de Murcia.

Mederos, Alicia (2019), "Josefina de la Torre. La 'muchacha-isla”, en Yasmina Romero Morales y Alba Sabina Pérez (eds.), Escritoras canarias del siglo XX: de la invisibilidad al reconocimiento, Madrid: Ediciones La Palma, pp. 99-112.

Merlo, Pepa (2010), Peces en la tierra. Antología de mujeres poetas en torno a la Generación del 27, Sevilla: Fundación José Manuel Lara.

Plaza Agudo, Inmaculada (2012), "Modelos de identidad femenina en la España de posguerra: el teatro de Mercedes Ballesteros”, Hispania, 95, 1, pp. 24-36.

Porter, Dennis (1983), The Pursuit of Crime. Art and Ideology in Detective Fiction, New Haven: Yale University Press.

Pujante Segura, Carmen M. (2010), “Notas para una recreación históricotemática de la novela corta española: a propósito de las escritoras en $L a$ Novela del Sábado (1953-1955)", Castilla. Estudios de Literatura, 1, pp. 3859, <https://bit.ly/2YGHFhW> [consulta: 06/08/2019]. 
Resina, Joan Ramon (1997), El cadáver en la cocina. La novela criminal en la cultura del desencanto, Barcelona: Anthropos.

Reverón Alfonso, Juan Manuel (2007), Vida y obra de Claudio de la Torre, Santa Cruz de Tenerife: Ediciones Idea.

Rivero Grandoso, Javier (2016), Modelos urbanos y su proyección literaria en la novela criminal [tesis doctoral], Madrid: Universidad Complutense, $<$ https://eprints.ucm.es/38286/> [consulta: 06/08/2019].

Sánchez Zapatero, Javier (2006), "Apuntes para una perspectiva histórica del policiaco español”, en Álex Martín Escribá y Javier Sánchez Zapatero (coords.), Manuscrito criminal. Reflexiones sobre novela y cine negro, Salamanca: Librería Cervantes, pp. 69-84.

--- (2017), "Del pastiche a la transficcionalidad: reescrituras de Sherlock Holmes en España", Tropelías, 27, pp. 39-55 <https://bit.ly/2YsECuz> [consulta: 04/08/2019].

Sánchez Zapatero, Javier y Álex Martín Escribá (2011), "Del quiosco al best-seller: la novela policiaca en España”, en Ana Cabello (coord.), Aproximaciones a la literatura popular y de masas escrita en español (siglos XX $y$ XXI), Madrid: Los libros de la Catarata, pp. 93-108.

Santiago Mulas, Vicente de (2002), Historia externa de la novela criminal en España (1939-1975) [tesis doctoral], Madrid: Universidad Complutense de Madrid, , <https://eprints.ucm.es/3667/> [consulta: 07/08/2019].

Soler Gallo, Miguel (2017), "El ideal de masculinidad en la novela romántic efalangista: análisis de Una mujer de veinte años de Mercedes Ballesteros", Tonos Digital. Revista de estudios filológicos, 33, pp. 1-25<https://bit. ly/2Y8DHud> [consulta: 05/08/2019].

Spang, Kurt (2000), Géneros literarios, Madrid: Síntesis [1ª ed. 1993].

Torre, Claudio de la (1941 [13 de enero]), "A Fernando González Rodríguez" [carta inédita], Red de Bibliotecas de Canarias, Biblioteca Insular de Gran Canaria <https://bit.ly/2KluURK> [consulta: 06/08/2019].

Torre, Josefina de la (1939), Alarma en el Distrito Sur, Madrid: Gráficas Uguina.
--- (1944), El caserón del órgano, Madrid: Ediciones Océano.

Valles Calatrava, José R. (1991), La novela criminal española, Granada: Servicio de Publicaciones de la Universidad de Granada.

Vázquez de Parga, Salvador (1993), La novela policíaca en España, Barcelona: Ronsel.

--- (2000), Héroes y enamoradas. La novela popular española, Barcelona, Glénat.

Vázquez Montalbán, Manuel (1989), "Sobre la inexistencia de la novela policiaca en España”, en Juan Paredes Núñez (ed.), La novela policiaca española, Granada: Universidad de Granada, pp. 49-62.

Vosburg, Nancy (2011), "Spanish Women’s Crimen Fiction, 1980s-2000s: Subverting the Conventions of Genre and Gender", en Nancy Vosburg (ed.), Iberian Crime Fiction, Wiltshire: University of Wales Press, pp. 75-92. 